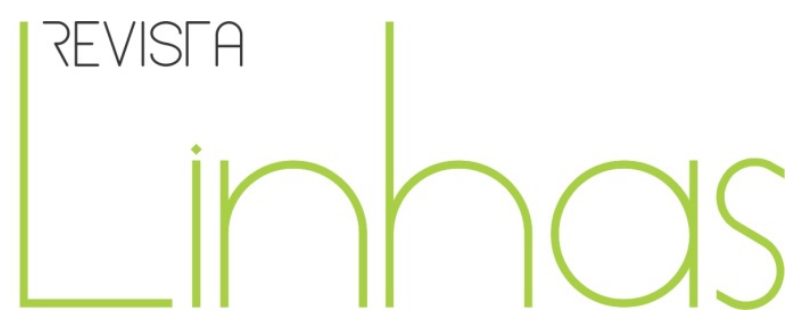

\title{
Uma tentativa de democratização universitária na França: história da universidade de Paris VIII Vincennes (1968- 1980) ${ }^{1}$
}

\section{Resumo}

Nos anos 1970, a Universidade de Vincennes, cujo departamento de sociologia foi fundado por Jean-Claude Passeron e o de filosofia por Michel Foucault, é o lugar de uma tentativa original de democratização da universidade francesa. Após descrevermos as circunstâncias de criação e o seu público, faremos um balanço pedagógico desta experiência pedagógica fora do comum, sabendo que esta universidade acolheu em massa estudantes sem bacharelado, assim como uma grande proporção de estudantes assalariados. Um balanço um tanto modesto, uma vez que, sob a pressão política do momento, da desordem instaurada, assim como das oposições entre classes latentes, os professores e os estudantes não conseguiram entrar em acordo sobre princípios pedagógicos comuns mínimos. E um dos resultados no mínimo paradoxal dessa experiência é que os vincennois inventaram uma espécie de mercado livre acadêmico no qual reinou a concorrência carismática entre todos os professores.

Palavras-chave: Universidade de Vincennes; Democratização; Pedagogia; Jean-Claude Passeron; Disciplina.

\author{
Charles Soulié \\ Doutor em Sociologia pela École \\ des Hautes Études en Sciences \\ Sociales - EHESS - Paris/França \\ charles.soulie@neuf.fr
}

\begin{abstract}
Para citar este artigo:
SOULIÉ, Charles. Uma tentativa de democratização universitária na França: história da universidade de Paris VIII Vincennes (1968-1980). Revista Linhas. Florianópolis, v. 15, n. 29, p. 42-70, jul./dez. 2014. Título original: Un essai de démocratisation universitaire en France: histoire de l'université de Paris VIII Vincennes (19681980). Traduzido por Fernando Coelho, com revisão técnica de Ione Ribeiro Valle.
\end{abstract}

\section{DOI: $10.5965 / 1984723815292014042$}

http://dx.doi.org/10.5965/1984723815292014042

\footnotetext{
${ }^{1}$ Este artigo tem como base uma obra coletiva intitulada Un mythe à détruire? Origines et destin du Centre universitaire expérimental de Vincennes, dirigida por Charles Soulié (2012).

* Artigo traduzido por Fernando Coelho - zeffiretto@gmail.com, com revisão técnica de Ione Ribeiro Valle - ione.valle@ufsc.br.
} 


\title{
An attempt to university democratization in France: the history of the University of Paris VIII Vincennes (1968-1980)
}

\begin{abstract}
During the 1970s, the University of Vincennes - whose Department of Sociology was founded by Jean-Claude Passeron, its Department of Philosophy by Michel Foucault - was the site of a novel project to democratize the French university. After describing the University's circumstances of creation and its public, we will sum up the pedagogical lessons of this unusual educational experiment. It was a university that welcomed masses of students without a baccalauréat (secondary school diploma), along with a very large proportion of working students. Yet our evaluation must be tempered by the fact that - given the political pressures of the times, the disorderly atmosphere, the latent class conflicts - its teachers and students never really managed to agree on a minimum set of shared pedagogical principles. And one of the rather paradoxical results of this experiment was that Vincennes would invent a sort of academic free market, ruled by charismatic competition between all its teachers.
\end{abstract}

Keywords: Université de Vincennes; Democratization; Pedagogy; Jean-Claude Passeron; Discipline. 


\section{Introdução}

Quando, em 1964, Pierre Bourdieu e Jean-Claude Passeron publicam Os herdeiros, a universidade francesa enfrenta uma verdadeira crise de crescimento. Assim, entre 1945 e 1960, o número de estudantes passa de 123.000 a 214.000. Mas esse crescimento dispara a partir dos anos 1960, sendo a taxa de progressão anual superior a 10\%. Desse modo, no início do semestre de 1967, registram-se 504.540 estudantes.

Esta expansão acelerada vem acompanhada por uma mudança na composição escolar e social do público estudantil, a qual não deixa de suscitar reações malthusianas no corpo docente. Assim, no início dos anos 1960,

se vê o tom subir ou tornar-se amargo nas reportagens da mídia que descobrem a 'grande miséria das universidades', assim como nas 'tomadas da palavra nos auditórios', que começam a 'superlotar', ou nos apartes sentenciosos dos professores que não encontrar mais nos seus estudantes os mimetismos de discípulos ou de sucessores: 'o nível dos estudantes diminuiria' ano após ano, ainda mais rápido do que podiam se resignar os professores que gostam de repetir, de ano em ano, esta frase de memória perdida? (PASSERON, 1986, p. 368)

Essa massificação leva o governo a contratar um grande número de novos professores. Assim, entre 1959 e 1967, o número de professores, de mestres de conferência ${ }^{2}$ e de mestres assistentes de letras e ciências humanas passa de 974 a 3.908. Isso também é acompanhado por uma mudança na estrutura dos empregos, o número de professores subalternos cresce muito mais rapidamente do que o dos professores, o que limita consideravelmente as possibilidades de carreira tendo repercussões políticas importantes em maio de $68^{3}$.

Mas ela também leva à criação de novos estabelecimentos universitários públicos, já presentes no interior. Assim, em 1968 na França existem 40 cidades universitárias contra 24 em 1939 (PROST, 2004, p. 313). Esse crescimento diz respeito também à região parisiense, com muitos artigos de jornal enfatizando o fato de que "a

\footnotetext{
${ }^{2}$ Posição atribuída ao professor universitário no início da carreira. (N.T.)

${ }^{3}$ Sobre este aspecto, ver: Bourdieu (1984), mais especificamente o capítulo intitulado "O momento crítico".
} 
Sorbonne está sufocada dentro de suas paredes". A Universidade de Orsay, voltada às ciências, abre suas portas em 1958. E a de Nanterre, "filha da Sorbonne", dedicada às letras e às ciências humanas, assim como ao direito e à economia, e que, com seu departamento de sociologia onde ensinam notadamente Alain Touraine, Michel Crozier, Henri Mendras, Henri Lefebvre, etc., que seria um dos epicentros da revolta universitária de maio de 68, é inaugurada em 1964.

Da mesma maneira, no outono de 68 , e em resposta às críticas dirigidas em maio de 68 à universidade tradicional (elitismo, imobilismo intelectual, ausência de democracia interna, etc.), o poder gaullista aprova uma Lei de orientação que transforma profundamente o estatuto das universidades francesas. Elas passam portanto a ter uma primeira forma de autonomia e ampliam a "participação" (ou seja, formas de democracia interna), assim como a pluridisciplinaridade. Esse poder decide abrir em caráter de urgência dois centros universitários experimentais em Paris, com finalidades bem divergentes: Dauphine, dedicada às ciências administrativas e implantada nos "bairros chiques" da capital, e Vincennes, um pouco isolada, construída no centro de um grande bosque parisiense, no caso o Bosque de Vincennes, e voltada às letras e às ciências humanas.

Neste artigo, interessamo-nos pelo destino da Universidade de Vincennes, cujo objetivo principal era democratizar o acesso aos estudos universitários. Universidade na qual se engaja principalmente Jean-Claude Passeron, futuro diretor de seu departamento de sociologia e que, na direção de seus trabalhos com Pierre Bourdieu, pensa poder encontrar aí um lugar de experimentação de uma pedagogia mais racional. ${ }^{4}$ Descreveremos em seguida as circunstâncias de criação desta universidade fora do comum, seu público, para enfim fazer um balanço pedagógico dessa experiência.

\footnotetext{
${ }^{4}$ Lembremos que quando, em 1970, Pierre Bourdieu e Jean-Claude Passeron publicam A reprodução, Passeron é professor em Vincennes.
} 


\section{Uma criação sob forte tensão política}

Ao abrir os centros universitários experimentais de Dauphine e Vincennes, o poder gaullista tem em vista um duplo objetivo. De um lado, mostrar que ouviu as críticas enunciadas em maio e permitir aos inovadores fazer experimentos pedagógicos e científicos suscetíveis de, caso estes deem certo, irrigar o conjunto do ensino superior. Mas também afastar do centro de Paris, e mais precisamente do Quartier Latin, seus elementos mais perturbadores, facilitando sobretudo a "volta à ordem". E, na verdade, na época e como consequência dos acontecimentos de maio de 68, uma parte da juventude estudantil acredita na iminência de uma revolução e muitas universidades são locais de intensa contestação política. Os movimentos políticos de extrema esquerda, e sobretudo os de inspiração maoista, estão em pleno desenvolvimento e marxismo e pensamento crítico se difundem amplamente, tanto entre os estudantes quanto entre os professores.

Edgar Faure é ministro da Educação Nacional na época. É um político hábil, que compreende claramente o sentido da história. Assim, no outono de 1968 e durante a votação da Lei de orientação no senado, ele declara: “Não há exemplo na História de que uma revolução tenha sido feita apenas por revolucionários. É preciso, portanto, que esses revolucionários arrastem consigo reformistas: mas faremos tudo o que for preciso para que eles não consigam." (FAURE, 1969, p. 108-109). A abertura desses dois centros universitários experimentais, assim como as contratações massivas de professorespesquisadores após 1968, são alguns dos elementos chaves da estratégia governamental da época. Uma cifra dá uma ideia da amplitude dos gastos orçamentários na matéria. Em 1967 existiam 3.908 professores-pesquisadores de letras e ciências humanas. Em 1974, eles são 8.011. Ou seja, a duplicação do corpo em sete anos. Ao passo que, no mesmo período, o total de estudantes de letras e de ciências humanas passou de 157.000 a 248.000.

Contratou-se, portanto, muito após 1968 e com frequência em condições pouco ortodoxas. O que se explica sobretudo pela destruição do poder mandarínico à moda antiga, e portanto do poder gerontocrático, e que resulta sobretudo em um período de 
interregno prolongado propício aos experimentos, assim como às derivas de todo gênero. Essas contratações massivas - que param claramente após 1974 sendo retomadas apenas no final dos anos 1980 em favor da segunda massificação universitária - estão na origem de gerações universitárias fortemente diferenciadas. Isso que terá efeitos de longo prazo tanto na história institucional da universidade francesa, quanto na sua história intelectual.

No início, Vincennes era essencialmente um sonho de professores e estes temendo ser ultrapassados pelos estudantes mais radicais - vão mantê-los a distância o maior tempo possível. Mas os professores não formam um grupo homogêneo e, de modo geral, podemos dividi-los em dois grupos, ou talvez três, se acrescentarmos aqueles que verão primeiramente em Vincennes uma oportunidade para fazer carreira, ou para voltar o mais rápido possível à capital. Na verdade, e em razão da centralização extrema do sistema escolar e universitário, mas também de pesquisa, editorial, etc., francês, assim como da concentração de todas as formas de capitais em Paris, uma carreira acadêmica bem sucedida devia necessariamente ser concluída na capital e, mais precisamente, na Sorbonne ou no Colégio de França.

O primeiro grupo de professores, o mais visível na mídia e sobre o qual, aliás, discorrerá longamente a revista da esquerda intelectual da época, no caso o Nouvel Observateur, é constituído pela vanguarda intelectual francesa (e portanto parisiense...) dos anos 60 e está sobretudo preocupado com questões de pesquisa. Encontram-se, portanto, em Vincennes inovadores de todo gênero, que penam para encontrar um lugar na universidade tradicional, e que, em maio de 68, reúnem-se aos estudantes na sua crítica à universidade, assim como à sociedade em geral. Descreveremos aqui precisamente os dos departamentos de filosofia e de sociologia, sobre os quais dispomos de mais informações e que desempenharão um papel chave em nosso propósito.

Assim, na filosofia, podemos citar os nomes de Michel Foucault, Alain Badiou, Jacques Rancière, François Châtelet, Michel Serres e, além deles, Gilles Deleuze, JeanFrançois Lyotard, etc. O investimento de Michel Foucault na experiência de Vincennes faz grande alarde. E é ele que contrata os primeiros professores do departamento de filosofia, do qual ele será, aliás, o primeiro diretor. Portanto, em razão da conjuntura 
política do momento, essas contratações realizam-se a partir de bases tanto políticas quanto científicas. Na verdade, no início Foucault deseja criar "um centro de análise da ciência na sua dimensão política", o qual articularia epistemologia e análise política. Mas quando chega a Vincennes, Foucault está vindo da Tunísia. Ele “não fez 68”, como se disse na época, ou seja, ele não esteve "nas barricadas", nas comissões de reflexão da Sorbonne, etc. Portanto, ele conhece pouco o ambiente dos jovens filósofos engajados. Assim, para a contratação, ele recorre a Alain Badiou.

Na época Badiou, aluno da Escola Normal Superior, filho de normalistas egressos dessa escola, aluno de Althusser e de Canguilhem, e cujo pai, professor de ciências, tinha sido prefeito da grande cidade de Toulouse, tinha 31 anos. Militante maoista muito ativo e eficaz em assembleias gerais, ele aconselha Foucault a procurar os contratados na nova geração de normalistas filósofos da Escola Normal Superior, alunos de Althusser e Lacan. Claramente, os critérios políticos desempenham um papel central nessas contratações. E, para contrabalançar a influência maoista amplamente majoritária, Foucault contrata Henri Weber, um dirigente trotskista, assim como Etienne Balibar, membro do Partido Comunista Francês. Enfim, e para desempenhar um papel de moderador neste ambiente de forte militância, ele recorre a François Châtelet.

Do lado dos sociólogos, destacamos os nomes de Jean-Claude Passeron, Robert Castel, Emmanuel Terray, Nicos Poulantzas, etc. É portanto Jean-Claude Passeron, com 38 anos na época e mestre de conferências na Universidade de Nantes, cujo pai era assalariado e a mãe professora das séries iniciais, que está na origem do departamento de sociologia de Vincennes. E é ele que, com a ajuda entre outros de Michel Foucault, mais velho que ele a quem conhecera e admirara quando aluno na Escola Normal Superior, contrata seus primeiros professores, buscando sobretudo dentre os althusserianos 5 . Pierre Bourdieu também é solicitado, mas recusa a oferta. Eis o que diz sobre isso JeanClaude Passeron em uma de suas entrevistas: “Aron dizia: 'É muito perigoso' e mesmo Bourdieu, que aliás recusou. [...] Bourdieu compreendeu logo - pelo menos isso em nada

\footnotetext{
${ }^{5}$ Sublinhamos que, em 1966, Jean-Claude Passeron publicou com Gérald Antoine, um gramático linguista futuro membro do gabinete de Edgar Faure, uma obra intitulada La Réforme de l'université, a qual insistia especialmente sobre a "ingenuidade sociológica dos tecnocratas". Ela continha um grande número de excertos muito interessantes sobre a pedagogia universitária da época, sobre os equívocos da democratização, etc.
} 
o divertia. Ele me disse: ‘Não, mas você é completamente louco de lidar com essa galera'. Efetivamente, ele já estava em campanha para o Colégio de França."

Quando se lança à aventura de Vincennes, Jean-Claude Passeron conta em especial com Robert Castel, com quem, em 1967, publica Éducation, développement et démocratie. De origem popular e interiorana (seu pai era um simples assalariado da construção de pontes e pavimentos e em sua família havia apenas dois livros), Robert Castel é professor na Sorbonne, onde vivencia os acontecimentos de 1968: "Eu estava na Sorbonne, e poderia ter resistido. Mas quando houve esta oportunidade de Vincennes, não que eu fosse ultraesquerdista e não pensasse que se faria a revolução, mas tentar contribuir com uma universidade mais aberta, democrática, menos tradicional...”6.

Com o departamento de sociologia de Vincennes recebendo um número crescente de estudantes, Jean-Claude Passeron e sua equipe tiveram que contratar rapidamente um número de professores de nível subalterno. E esses últimos, geralmente com pouca formação, mas frequentemente muito politizados e de esquerda, exercerão, com o apoio dos estudantes assim como da fração mais radical dos professores titulares, uma forte pressão política tanto sobre o funcionamento da instituição, as contratações de professores, quanto sobre a constituição dos programas, das modalidades de ensino, etc.

Na época, vanguarda intelectual e vanguarda política parecem se unir na crítica à ordem intelectual, institucional, social e política existente. Parecem, pois os quiproquós, mal-entendidos, fenômenos de instrumentalização recíprocos, são numerosos. E, de fato, legitimidade intelectual e legitimidade política não estão necessariamente em harmonia num ambiente político de alta voltagem tal como o das faculdades francesas do pós-68, e os conflitos entre gerações universitárias são por vezes agudos. Do mesmo modo, as manifestações de terrorismo, tanto intelectual quanto político, sobretudo feitas pelos grupos maoistas e inspiradas nas práticas da "revolução cultural" chinesa, serão inúmeras.

\footnotetext{
${ }^{6}$ Entrevista realizada com Robert Castel em 06 de dezembro de 2007.
} 
O segundo grupo de professores que se lançou na experiência de Vincennes estava constituído por professores frequentemente menos conhecidos, mas preocupados em renovar suas práticas, tanto pedagógicas quanto científicas, num sentido ao mesmo tempo democrático e modernista. Eles frequentemente eram, para empregar o vocabulário político da época, "reformistas", ou seja, professores que desejavam aproveitar as dinâmicas introduzidas pelos estudantes na universidade em 68 para renovar os programas, transformar a relação pedagógica e, sobretudo, abrir a universidade para o mundo, assim como para novos públicos.

Dentre eles, podemos pensar nos professores do departamento anglo-americano ou de psicologia experimental, que na época eram grandes departamentos e que, por essa razão, quase formavam por si sós uma pequena faculdade com todos os problemas que a gestão de um grande número de estudantes assim como de professores implica? Esses professores, próximos do Partido Comunista francês e frequentemente de origem mais popular do que os professores de vanguarda de renome internacional, exerceram um papel-chave pelo fato de assumirem o papel - um pouco ingrato na época - da gestão cotidiana de uma instituição altamente paradoxal, uma vez que ela reputava-se antiinstitucional. Num universo simbolicamente dominado pelos valores críticos e libertários, associados especialmente às personalidades intelectuais da época, eles assumiram as posições de poder local participando sobretudo do funcionamento da instituição. O que levou por vezes a enfrentamentos políticos violentos.

Por exemplo, no dia 18 de junho de 1969, durante as primeiras eleições locais visando designar as instâncias de governo do Centro, os esquerdistas e antiparticipacionistas atiram as urnas eleitorais pela janela. Em reação, professores do Centro redigem um "Apelo a todos os professores", assinado por 150 deles, fazendo apelo "à responsabilidade de cada professor": “Diante desses acontecimentos, cada professor é posto diante das seguintes alternativas: ou apoia em nome de uma ideologia que decidiu 'a destruição da Universidade', ou se mostra indiferente aos acontecimentos daquela manhã e, portanto, ao fechamento de Vincennes com suas implicações, ou

\footnotetext{
7 Sobre as origens, a contratação e a política do departamento anglo-americano de Vincennes, ver o artigo de Pouly (2012, p. 281 e seguintes).
} 
decide assumir suas responsabilidade e agir.” Em consequência, os signatários se obrigam “a informar sistematicamente em seus trabalhos práticos os seus estudantes e a se fazer pessoalmente presentes no dia da votação para garantir uma consulta livre." (LEGOIS, 2012, p. 266). Tudo isso explica em especial a ingovernabilidade crônica desta universidade que se prolonga até mais ou menos 1971 por meio de uma alternância acelerada dos decanos. De resto, o fenômeno não é específico de Vincennes e pode ser observado também na Universidade de Dauphine.

\section{Um público fora das normas}

$\mathrm{Na}$ origem, Vincennes tem dificuldades para encontrar seus primeiros estudantes. Por quê? Sem dúvida em razão da imprecisão dos objetivos de um Centro com finalidade experimental. Na verdade, nos anos 1960, as faculdades de letras e ciências humanas francesas têm como função essencial formar professores. Ora, o projeto de Vincennes, que quer abrir-se amplamente para o mundo contemporâneo, para as novas disciplinas, mas também para os empregos do futuro, parece querer romper radicalmente com esta função tradicional. Donde, sem dúvida, a reticência a engajar-se por parte de uma parcela de estudantes e sobretudo os mais interessados na docência, que também são com frequência os melhor dotados escolarmente e que, por isso, permanecerão nas universidades mais tradicionais.

$\mathrm{Na}$ origem, Vincennes atrai essencialmente estudantes do primeiro ano, muitos deles vindos da Sorbonne ou de Nanterre e que apresentam um perfil que se poderia qualificar de herdeiros críticos. Parte deles é, portanto, muito militante e deseja sobretudo fazer de Vincennes "uma base vermelha" que lhes permitirá "abater o capitalismo". Mas há também muitos estudantes mais "reformistas", que por exemplo seguiram seus professores que migraram da Sorbonne para Vincennes. Esse é, por exemplo, o caso de história, ou de literatura francesa, departamentos politicamente menos radicais que os de filosofia, sociologia ou artes plásticas. Mas também podemos 
falar dos estudantes comuns que encontraram lá uma universidade particularmente acolhedora no plano das formalidades de matrícula, das exigências acadêmicas, etc. Enfim, desde o primeiro ano, encontra-se uma proporção não negligenciável de estudantes sem bacharelado (18\%), o que nos leva ao centro do nosso objeto.

$\mathrm{Na}$ verdade, a grande originalidade de Vincennes residiria no seu público, pois desde a abertura ela se abre resolutamente a uma população habitualmente rejeitada pela universidade: no caso, a de estudantes sem bacharelado e de assalariados. Graças sobretudo à multiplicação das aulas no período noturno, nos sábados, à grande flexibilidade dos seus cursos e às facilidades para se matricular, Vincennes atrai um público original. Assim, em 1975, ela conta com 38\% de estudantes sem bacharelado, 60\% de assalariados em tempo integral. Em consequência, a média de idade dos estudantes de Vincennes passa de 27 anos em 1973-1974 para 29 anos em 1978-1979, contra 22 anos nas outras universidades francesas.

Claramente, esta universidade responde a uma forte demanda social. Inicialmente prevista para 7.000 estudantes, ela conta com 32.000 em 1979. Ou seja, quatro vezes mais, ao passo que os ambientes, os créditos, assim como as contratações de professores e de pessoal, não crescem na mesma proporção. Em consequência, após um primeiro período quase de luxo, que provocava inveja nas outras universidades, o que se vê é sua instalação numa miséria material crônica. O Ministério ao recusar às outras universidades o direito de acolher estudantes sem bacharelado enquanto Vincennes aceitava todos os que se candidatavam, muito cedo se torna vítima do seu sucesso.

Enfim, última característica do público de Vincennes, a grande proporção de estudantes estrangeiros. Assim, em 1976, Vincennes conta com 46\% de estudantes estrangeiros $^{8}$. E ela acolhe também um bom número de professores estrangeiros, dentre os quais refugiados políticos ${ }^{9}$. Ela era portanto a universidade mais estrangeira da França,

\footnotetext{
${ }^{8}$ Entre 1977-1978 Vincennes acolhia 14.817 estudantes estrangeiros, sendo 1.677 americanos. Dentre eles, em ordem decrescente, 297 colombianos, 262 brasileiros, 236 chilenos, 187 argentinos, etc. Sobre esse aspecto, ver: Le Gall e Soulié (2012, p. 393-422).

${ }^{9}$ Por exemplo, após o golpe militar de Pinochet no Chile, Vincennes acolhe vários professores chilenos nos seus departamentos de história, assim como de sociologia. Igualmente, no início dos anos 1970 o brasileiro José de Castro ministra aulas em Vincennes. Esse também é o caso de Mário Soares, futuro presidente da República de Portugal, expulso em 1970 de seu país pelo governo ditatorial de Marcello Caetano. Sobre
} 
o que ela continua sendo hoje. Se se quiser descrever estruturalmente o público de Vincennes, pode-se dizer que ele é a antítese, quase perfeita, do público particularmente padronizado, e selecionado, tanto escolar quanto socialmente, das classes preparatórias $^{10}$ e das grandes escolas ${ }^{11}$ francesas. Classes, escolas que, na França, concentram uma boa parte da elite escolar do país e de onde provém, aliás, a maioria dos professores mais renomados de Vincennes. Estes se confrontam, consequentemente, com uma distância escolar, social e cultural máxima nas suas práticas pedagógicas cotidianas.

Para retomar o título de um cartaz militante da época, pode-se dizer que, num belo arroubo de generosidade coletiva mais ou menos utópica, Vincennes tentara ser uma "Universidade aberta a todos", ou ainda "aos trabalhadores". Mas não é porque uma instituição abre formalmente suas portas a todos, e, portanto, que todo mundo entra, que todo mundo retira igual proveito de sua passagem pela referida instituição ${ }^{12}$. Por exemplo, se se compara a origem social dos estudantes de Vincennes com a dos estudantes das outras universidades, observa-se que, afinal de contas, ela está muito próxima. E que, como nas outras universidades, a admissão social se eleva à medida que se sobe no curso.

Quadro 1: A origem social dos estudantes na França e em Vincennes em 1975-1976.

\begin{tabular}{|l|c|c|}
\hline & $\begin{array}{c}\text { França } \\
\text { (letras e ciências } \\
\text { humanas) - \% }\end{array}$ & $\begin{array}{c}\text { Vincennes } \\
\text { (conjunto das } \\
\text { disciplinas) - \% }\end{array}$ \\
\hline Profissão liberal, nível supérieur & 29,3 & 28,7 \\
\hline Nível médio & 17,8 & 18,7 \\
\hline Assalariado & 10,2 & 9,8 \\
\hline Dono de indústria, de comércio, agricultor & 16,2 & 16,2 \\
\hline Operário, pessoal de serviço & 16,1 & 16,5 \\
\hline
\end{tabular}

esses dois professores, ver: Bué (2009, p. 126-129).

${ }^{10}$ Classes especiais, após a conclusão do ensino médio, que preparam para o ingresso nas grandes escolas. (N.T.)

${ }^{11}$ As grandes escolas formam os futuros dirigentes principalmente nas áreas tecnológicas e administrativas, propondo-lhes um ensino múltiplo ou específico (com a duração de no mínimo cinco anos após o ensino médio) reconhecido pelo Estado e assegurando-lhes as melhores oportunidades de acesso aos cargos públicos e empresariais de maior prestígio. (N.T.)

${ }_{12}$ Por analogia, pode-se pensar aqui no que era a frequência aos museus. Na verdade, sua gratuidade pontual (quer no domingo ou em outro dia) não é suficiente para assegurar a democratização de seu público. De fato, esta supõe a aquisição prévia de certo capital cultural, assim como de certas disposições cultas. Sobre esse aspecto, ver: Bourdieu e Darbel (1966). 


\begin{tabular}{|l|c|c|}
\hline Outros, sem profissão & 10,3 & 10,1 \\
\hline Total (\%) & $100 \%$ & $100 \%$ \\
\hline Total geral & 195.671 & 15.612 \\
\hline
\end{tabular}

Campo: somente estudantes franceses, fora os indeterminados.

Fonte: Soulié (2012, p. 211).

Em seguida, a propósito dos sem bacharelado, observa-se que o curso de Vincennes, que mistura estudantes com e sem bacharelado, não parece muito adaptado, uma vez que a parcela deles passa de $46 \%$ no primeiro ciclo para $13 \%$ no terceiro ciclo. Além disso, esses estudantes sem bacharelado apresentam um perfil muito específico, uma vez que a maioria tem o "nível de bacharel”, o que acaba por aproximá-los muito dos estudantes comuns. Mas, em se tratando de assalariados que retomam os estudos, e que frequentemente trabalham em tempo integral, eles são claramente mais velhos que os estudantes tradicionais e, portanto, levam mais tempo para concluir seus estudos.

Quadro 2: A origem escolar dos estudantes de Vincennes segundo o ciclo em 1976-1977

\begin{tabular}{|l|c|c|c|c|}
\hline & $\begin{array}{c}\mathbf{1}^{\circ} \text { ciclo } \\
\%\end{array}$ & $\begin{array}{c}\mathbf{2}^{\circ} \text { ciclo } \\
\%\end{array}$ & $\begin{array}{c}3^{\circ} \text { ciclo } \\
\%\end{array}$ & Conjunto \% \\
\hline Estudantes franceses com bacharelado & 29,0 & 43,0 & 46,0 & 35,0 \\
\hline Estudantes franceses sem bacharelado & 22,0 & 17,0 & 8,0 & 20,0 \\
\hline Estudantes estrangeiros com bacharelado & 24,0 & 28,0 & 41,0 & 26,0 \\
\hline Estudantes estrangeiros sem bacharelado & 24,0 & 12,0 & 5,0 & 19,0 \\
\hline Total (\%) & $100 \%$ & $100 \%$ & $100 \%$ & $100 \%$ \\
\hline Total geral & 17.501 & 8.953 & 1.716 & 28.170 \\
\hline
\end{tabular}

Fonte: Soulié (2012, p. 208).

Enfim, analisando as profissões exercidas por esses assalariados, nota-se que os operários são raros e que Vincennes já responde a uma demanda de formação contínua, sobretudo generalista, que emana essencialmente das profissões intermediárias, ou de empregados, provenientes do setor terciário e mais especificamente dos setores educacionais, sociais, paramédicos e artísticos, setores esses particularmente ativos em maio de 68 e daí em diante. Enfim, a "classe operária” - objeto na época de tantos discursos, de tantos fantasmas políticos - não está verdadeiramente presente em massa em Vincennes. Ou então, trata-se de indivíduos muito atípicos, com trajetórias conturbadas, com herança cultural, social, política, religiosa, etc., particularmente 
complexa e frequentemente já inseridos num processo de autodidatismo pela via do sindicalismo, da política, etc. (FOSSE-POLLIAK, 1991).

Na verdade, seja no plano das características sociais ou escolares, tudo se passa como se elas estivessem essencialmente à margem do público universitário habitual, ou melhor, que Vincennes conseguiria conquistar um novo público. Essa extensão do público universitário a outras populações, sobretudo mais velhas, atinge, aliás, o conjunto das universidades francesas dos anos 70, ainda que num grau menor. E tudo se passa como se na época a universidade francesa respondesse a uma forte demanda social, a um “desejo de aprender", para retomar o título de uma obra da época dedicada a Vincennes (BRUNET et al., 1979), característica de toda uma geração e sobretudo nutrida pela onda de questionamentos, aspirações, interrogações coletivas iniciadas em maio de 68.

Vejamos por exemplo como Jean-François Le Ny, um professor de psicologia experimental de Vincennes de origem popular e provinciana, próximo do Partido Comunista Francês, e que também foi um dos mais ardentes participantes, descreve o público desta universidade:

havia na região parisiense, no final dos anos 1960, várias dezenas de milhares de jovens homens e mulheres que as vicissitudes da existência tinham impedido de fazer o bacharelado e de seguir estudos universitários, ainda que fossem intrinsecamente capazes. Eles, naquele período de pleno emprego, frequentemente já possuíam uma situação profissional e, geralmente, haviam adquirido um nível de competência real que ultrapassava sensivelmente o dos diplomas que tinham. Foi esta população, de fato fortemente autosselecionada, que veio massivamente a Vincennes, ao mesmo tempo para completar seus conhecimentos e obter diplomas oficiais, que representavam o único meio, no sistema francês, de acessar a melhores postos e a remunerações mais elevadas. Vincennes desempenhou portanto, durante uma década, e a despeito de todas as vicissitudes, um formidável papel social e cultural de recuperação universitária e de formação de alto nível para adultos. [...] Mas pouco a pouco, parece-me, esta "mina" ou este "estoque", como se diz com desaire, de capacidades e de desejos sociais diminuiu e acabou se esgotando. (Apud PAROT e RICHELLE, 1992, p. 277-278) 


\section{Vincennes ou o triunfo da pedagogia carismática?}

Por sua abertura máxima, pela diversificação dos seus cursos e pelo caráter inovador do seu ensino, Vincennes procuraria responder a uma demanda social, mas também intelectual, difusa, fortemente ligada a uma conjuntura histórica determinada. E parece que a filosofia de um Gilles Deleuze, por exemplo, que alguns, localmente, gostariam de elevar a ícone da Paris VIII ao rebatizar com seu nome essa universidade, oferece uma bela síntese do espírito de Vincennes na época.

Mas tudo isso é muito paradoxal. Na verdade, por um lado Vincennes soube, claramente, responder a uma forte demanda social e intelectual, ao ponto de tornar-se um mito e ser uma das universidades francesas mais conhecidas no exterior. Mas por outro, o balanço em matéria de democratização universitária parece modesto e os mecanismos de reprodução das desigualdades sociais e escolares parecem ter funcionado, tanto aqui como alhures.

Para compreender esse paradoxo, é necessário interessar-se pelo funcionamento pedagógico da instituição. Mas a tarefa não é fácil, pois é difícil objetivar sistematicamente as práticas pedagógicas dos professores, assim como as práticas de estudos dos estudantes. Os arquivos não dizem muita coisa acerca disso e os testemunhos não são muito esclarecedores. Igualmente, essas práticas eram muito diversas de um departamento a outro, assim como de um professor a outro. Daí a dificuldade de apreender o resultado do conjunto, o que coloca o pesquisador diante de uma espécie de caixa preta, que remete, aliás, às dificuldades que encontramos ainda hoje para objetivar nossas próprias práticas. Ou, dito de outro modo, ao nosso inconsciente pedagógico, quer ele seja individual ou coletivo.

E, de fato, é particularmente difícil ter uma ideia clara da sua prática assim como dos efeitos tanto do seu ensino, quanto do que resulta do coletivo de professores. Dispomos, certamente, de informações sobre o número de diplomas conferidos, sobre os 
planos de ensino, dos diários de avaliação, e até mesmo de trabalhos relativos "às categorias de juízo professoral”, de trabalhos dos estudantes, etc., mas cada um sente a falta cruel de mediações que nos permitiriam saber melhor o que fazemos quando ensinamos e, essencialmente, quando falamos... Enfim, nossa prática e sobretudo seus efeitos são ainda muito obscuros. E foi isso o que fez com que, trabalhando com muita curiosidade sobre a história de Vincennes, não tenhamos tido a impressão de trabalhar sobre um passado, mas sobre o presente. E, finalmente, somente conseguimos compreender esse passado ao nos voltarmos à nossa própria experiência. Mas isso corre o risco de levar a uma forma de círculo um pouco anistórico, uma vez que acabamos deixando de lado especificidades históricas da época.

Estudando as práticas pedagógicas de Vincennes, é inevitável surpreender-se com a permanência do curso magistral, que fora, contudo, tão vilipendiado em maio de 68 em razão de seu caráter autoritário e elitista. Na verdade, o que se vê quando se assiste aos cursos filmados de Deleuze, Châtelet, Lyotard ou outros? Bom, um "grande professor" que fala num ambiente geralmente muito enfumaçado e estudantes que tomam notas.

Certamente, o humor político do momento faz com que alguns expectadores não hesitem em interpelar e, até mesmo, em admoestar publicamente o professor, a fim por exemplo de lembrá-lo da proeminência do político e, portanto, dos imperativos práticos, morais ou políticos, sobre o acadêmico, o intelectual ou o pedagógico. Mas esse dispositivo, em resumo muito tradicional, parece ter sido bastante recorrente, sobretudo nos cursos das principais personalidades de Vincennes e geralmente numa disciplina particularmente livresca e simbolicamente dominante como a filosofia em Vincennes, que, por essa razão, aliás, dá o tom tanto ideológico, político, quanto pedagógico a um número de outras disciplinas. Fato lamentado, aliás, por Jean-Claude Passeron.

Por exemplo, eis o que Michel Foucault diz sobre isso em 1971 em uma entrevista dada à Partisan Review:

Na França, criticou-se violentamente o sistema das conferências: o professor chega, fica atrás da sua mesa durante uma hora, diz o que tem 
para dizer, e o estudante não tem a possibilidade de discutir. Os reformistas preferem a fórmula do seminário, pelo fato de se basear na liberdade: o professor termina de impor suas ideias e o estudante tem o direito de falar. Isso é verdade... Mas você não acha que um professor que assume a responsabilidade por estudantes no início do ano, os faz trabalhar em pequenos grupos, os convida a entrar em seu próprio trabalho, compartilha com eles seus problemas e seus métodos, você não acha que, nessa fórmula, os estudantes podem ficar ainda mais deformados no final do seminário do que se tivessem simplesmente assistido a uma série de conferências? Eles não considerarão como adquirido, natural, evidente e absolutamente verdadeiro o que não é, afinal, senão o sistema, o código, a grade de seu professor? Eles não correm o risco de que o professor lhes imponha suas ideias de maneira muito mais insidiosa? Não quero defender a conferência a todo custo, mas me pergunto se ela não possui, para dizer a verdade, uma espécie de honestidade bruta, a menos que ela esclareça o que é: não a proclamação de uma verdade, mas a apresentação, em fase experimental, de um trabalho que tem suas hipóteses, seus métodos, e que portanto deixa o campo livre à crítica e às objeções: o estudante é livre para revelar suas inabilidades. Naturalmente, os seminários e grupos de trabalho são necessários, mas mais, creio eu, para permitir o exercício da liberdade do que para experimentar métodos.

Quando faço uma conferência um pouco dogmática, digo para mim mesmo: sou pago para levar aos estudantes certa forma e certo conteúdo de saber; devo construir minha conferência ou meu curso como se fabricasse um sapato, nem mais, nem menos. Concebo um objeto, tento fabricá-lo do melhor modo possível. Tenho muita dificuldade (nem sempre, é claro, mas com frequência), levo esse objeto à sala de conferências, mostro-o e, em seguida, deixo o público livre para fazer uso dele da maneira que lhe agrada. Considero-me mais como um artesão fabricando um objeto e oferecendo-o ao consumo do que como um mestre fazendo trabalhar seus escravos. ${ }^{13}$

Na verdade, parece ter havido certa divisão do trabalho pedagógico, mais ou menos renegada, entre professores, uns professando magistralmente e usando, portanto, uma pedagogia de tipo carismático, no fundo muito tradicional, enquanto outros empregam dispositivos mais interativos e se voltam mais à prática, ou seja, às tarefas auxiliares: sobretudo no quadro dos cursos introdutórios, de aprendizagens de

\footnotetext{
${ }^{13}$ Cf.: "Conversation avec Michel Foucault", texto reproduzido em Foucault (1994, p. 190-191). Esta apologia do curso magistral encontra-se também em Deleuze. E aí também ela é acompanhada de uma crítica da "discussão" em curso. Sobre esse aspecto, ver o que diz esse filósofo quando fala do "Professor" (DELEUZE, 2004) no filme dirigido por Pierre-André Boutang (2004).
} 
base, de metodologia, etc. E claramente esta divisão segue, grosso modo, a escala do prestígio intelectual ou político, ligada ao tempo de serviço, ao grau, ao sexo, etc.

Assim, nos departamentos nos quais os cursos eram menos estruturados formalmente - frequentemente aqueles cuja exigência de igualdade entre professores, mas também entre estudantes e professores, pessoal administrativo e técnico, era mais fortemente revindicada - essa divisão do trabalho não estava necessariamente formalizada numa espécie de organograma a priori, ou numa hierarquia funcional claramente explicitada. Ela resultava sobretudo da posição de cada um nas hierarquias simbólicas, políticas e finalmente sociais. Assim, nesses departamentos cada um parece, após alguns tateamentos iniciais ligados especialmente à novidade da experiência, ter encontrado, para falar como Aristóteles, seu "lugar natural”. Ou seja, aquele que melhor convém ao que ele era socialmente.

Em Vincennes, havia, portanto, uma grande distância entre o "professorzinho" dedicado às tarefas pedagógicas ordinárias e que, conforme o modelo do sacerdote membro de uma igreja bem hierarquizada, se consagra essencialmente às tarefas de evangelização e de elevação de laicos cheios de boa vontade escolar, frequentemente mais jovens, mais femininos, mais franceses e mais bacharéis que a média, e em fase de acumulação de um capital escolar que podia eventualmente transformar-se em moeda no mercado nacional dos concursos para contratação ${ }^{14}$ - tarefas que com frequência entram em acordo com suas convicções pedagógicas e democráticas mais profundas -, o professor substituto que entrou por critérios políticos, que trabalha com temas diretamente políticos objeto de sua tese (frequentemente de inspiração maoista no início do período) e com estudantes mais velhos que a média, muito politizados (ou que é preciso politizar a fim de fazer deles futuros militantes revolucionários) e a priori menos preocupados com a questão dos exercícios profissionais posteriores ${ }^{15}$, o professor

\footnotetext{
${ }^{14}$ Tipo de estudante mais comum em história, literatura francesa, geografia, línguas... Cursos que têm, e conservam um público mais "escolar" que os outros (e que com frequência trabalha na educação nacional) mantendo desde a origem uma ligação mais estreita com os concursos de seleção para o ensino secundário.

${ }^{15}$ Este tipo de estudante parece ter sido mais comum na sociologia, na ciência política, na economia, cursos de público mais masculino, cujos objetos são mais diretamente políticos; neles a taxa de estudantes estrangeiros é mais elevada e o direito de matrícula parece ter sido mais fraco, tanto do lado do estudante, quanto do professor, sendo que as disciplinas eruditas continuam sendo implicitamente reguladas pelos concursos do ensino secundário.
} 
substituto artista profissional, ou crítico de artes, em luta contra o intelectualismo ordinário, e sempre renascente, da universidade e em vias de reclassificação social (como foi dito por um deles, crítico nos Cahiers du cinéma, em matéria de gosto "a crítica tem privilégio sobre a universidade") $)^{16}$, ou ainda o professor substituto de uma disciplina como as ciências da educação, adepto da "dinâmica de grupo", ou do "potencial humano" ou da "bioenergia" em resposta às demandas de experimentação pedagógica, “desenvolvimento pessoal”, ou mais precisamente terapêuticos, de inspiração mais ou menos freudiana ou rousseauniana que emana de assalariados(as) provenientes do setor educacional, social ou paramédico. E para terminar - embora esta tipologia sumária mereça ser desenvolvida -, o virtuose, ou "grande intelectual" parisiense (frequentemente filósofo e geralmente dotado dos títulos escolares mais canônicos), conhecido antes de chegar a Vincennes, com disposições mais ou menos críticas e proféticas e capaz, ao mobilizar conceitos herdados da tradição e/ou "fabricados" para a ocasião (assim, Gilles Deleuze falará da filosofia como um lugar de "fabricação de conceitos" e do prazer que há, nesta disciplina, em superar "a censura" que exerce habitualmente a história da filosofia para chegar, enfim, a falar “em seu próprio nome”) (SOULIÉ, 1998, p. 62), de operar esse trabalho de retradução, de universalização das preocupações profanas de um público que excede muito os limites do da universidade tradicional. Neles ressoa o espírito do lugar que eles saberão interpretar, dar forma, sem necessariamente alienar-se $a$ isso.

\section{Mercado livre e concorrência carismática generalizada}

Sublinhamos a diversidade das práticas pedagógicas em função do estatuto, do gênero, da disciplina, do volume e das formas de capitais, etc., dos professores. Mas estas também são determinadas previamente pela estrutura formal dos programas de ensino, resultante da relação de forças/colaboração entre professores e estudantes, assim como

\footnotetext{
${ }^{16}$ Esta oposição encontra-se também em literatura francesa e em filosofia, onde à figura do "simples professor" se opõe a do "escritor", do "poeta" ou do "filósofo" e, de modo gera, a do "criador". E ela aparece também na figura, muito hierarquizante, do "pedagogo" e do "pesquisador", que se impõe particularmente no ensino superior.
} 
entre professores de níveis diferentes. E, na verdade, se desde o início nos grandes departamentos, como o de inglês ou de psicologia (o que, de fato, lhes impunha exigências de gerência a fim de regular minimamente fluxos importantes de estudantes e de professores) $)^{17}$, os estudantes deviam seguir um programa muito rígido com um sistema de disciplinas obrigatórias e hierarquizadas em função sobretudo do ano letivo e portanto do seu "nível", em outros departamentos eles são inteiramente livres para escolher as disciplinas que comporão seu curso.

Esse foi, por exemplo, o caso em filosofia, sociologia, artes, psicanálise, literatura francesa, etc. Daí a crítica de Deleuze, Châtelet e outros relativa à necessária “progressividade" dos estudos e seu elogio - paradoxal do ponto de vista do senso comum pedagógico - à extrema disparidade do público de Vincennes ${ }^{18}$. Público ao qual Deleuze elogia com frequência, referindo-se a ele como "esplendor de Vincennes".

Evidenciam-se portanto, entre outros, os efeitos de um a priori ético-político extremamente poderoso na época, o qual postulava a igualdade potencial de cada um diante do saber, propondo a cada estudante a autogestão de sua própria formação. Dizendo de outra maneira, a ideia é que cada um está mais bem colocado para saber o que precisa, onde está o seu “desejo", para identificar quem "Ihe fala”, quem lhe “interpela subjetivamente”. E portanto com qual professor é possível ocorrer um “encontro" de tipo mais ou menos carismático e análogo ao que acontece entre um mestre e seus discípulos ${ }^{19}$. E uma instituição universitária "aberta a todos", como Vincennes, deve responder a isso, oferecendo sobretudo um leque de ensinamentos suficientemente diversificados e o menos obrigatório possível. Esta diversidade e flexibilidade extremas favorecem, retomando mais uma vez o vocabulário deleuziano, a “multiplicidade" das "conexões” potenciais possíveis entre professores e estudantes. Lembremos que este período intelectual e histórico também se caracteriza, após o esgotamento de um marxismo leninista desde muito cedo percebido como "autoritário"

\footnotetext{
17 Sabendo que o departamento anglo-americano também teria que gerenciar boa parte da massa de estudantes de outros cursos que deveriam obrigatoriamente cursar disciplinas de língua para concluir a graduação.

${ }^{18}$ Sobre este aspecto, ver: Châtelet (1979, p. 126 e seguintes).

${ }^{19}$ Sobre a importância do tema do "encontro" na pedagogia deleuziana, ver: Charbonnier (2009).
} 
e criticado por seu "totalitarismo" pelos "novos filósofos" 20 , pelo desenvolvimento de uma “filosofia do desejo". Filosofia da qual Deleuze seria um dos grandes promotores, e que criticava severamente a versão psicanalítica e lacaniana (DELEUZE E GUATARRI, 1972).

Esta ausência de estruturação formal do curso era frequentemente acompanhada por uma coordenação pedagógica mínima entre professores. Assim, e sempre em filosofia, as reuniões pedagógicas eram inexistentes (a pedagogia sendo aliás tradicionalmente desprezada pelos filósofos, como explicita claramente uma fórmula corrente nesse meio e segundo a qual “A filosofia é por si mesma sua própria pedagogia.”), estando as apostas político-intelectuais em primeiro plano. Entretanto, no início, Michel Foucault queria “ter na mão" seu departamento. Mas a conjuntura política do momento, assim como o tipo de contratação que ele mesmo havia realizado, não lhe davam os meios para isso. E, finalmente, ele seria um tanto quanto ultrapassado por sua criatura, tendo se nutrido intelectual e politicamente da experiência de toda essa geração. Além disso, ele não permaneceu muito tempo em Vincennes, pois não suportava ser interpelado publicamente durante as aulas. E, desde 1970, ele se vincula ao Colégio de França, deixando portanto os cuidados da gestão do departamento de filosofia para François Châtelet.

A situação era relativamente semelhante em sociologia, lembrando que este curso ocupava uma posição simbolicamente dominada pela filosofia ${ }^{21}$. Se no início a equipe reunida por Passeron consegue pôr em prática um programa de estudo relativamente clássico com um mínimo de progressividade nos ensinamentos, rapidamente, e sob efeito sobretudo da pressão dos interesses e demandas de defesas políticas tanto dos estudantes quanto dos professores mais militantes, o curso se liberaliza e os programas de ensino se transformam. Assim, uma sociologia política de inspiração marxista, e mais ou menos escolástica em razão principalmente da impressão althusseriana inicial, assim como da ausência de formação prévia à pesquisa empírica dos

\footnotetext{
${ }^{20}$ Um deles (André Glucksmann) deu aulas temporariamente em Vincennes, passando do maoismo mais radical à nova filosofia.

${ }^{21}$ Esta reflexão busca livremente inspiração em "La sociologie à Vincennes: une discipline dispersée" (SOULIÉ, 2012, p. 315 e seguintes).
} 
professores contratados, ganha amplamente vantagem. Os cursos de estatística, suspeitos de serem ferramentas do pensamento de Estado, haviam desaparecido, os de metodologia (observação, entrevista, questionário) eram quase ausentes ou haviam sido substituídos por uma "pesquisa-ação", com objetivo inicialmente militante e de inspiração maoista (ou como dizia o presidente Mao, muito apreciado na época: "Quem não realizou enquetes não tem direito à palavra"), e as exigências em matéria de curso desapareceram completamente. Em 1971, cada estudante montava integralmente o seu currículo. O conteúdo preciso de cada graduação e, portanto, a formação recebida, variava consideravelmente de um estudante a outro.

Programa do departamento de sociologia de Vincennes em 1971-1972

\begin{tabular}{|c|c|}
\hline 1. CLASSE OPERÁRIA & Responsável(is) \\
\hline $\begin{array}{l}\text { Processo de implantação do PCF através de estudo crítico sobre a } \\
\text { origem do PC (82) }\end{array}$ & J. Trat \\
\hline $\begin{array}{l}\text { A integração dos sindicatos como aparelhos de Estado (problema da } \\
\text { participação) (173) }\end{array}$ & C. Weckerlé \\
\hline $\begin{array}{l}\text { Divisão e unidade da classe operária (imigrantes, tamanho das } \\
\text { empresas, setores de ponta) ( } 32 \text { ) }\end{array}$ & F. Duroux \\
\hline $\begin{array}{l}\text { O problema das alianças: classe operária, agricultores e classes médias } \\
\text { (Unidade da classe operária e unidade popular (132) }\end{array}$ & C. Weckerlé \\
\hline Os partidos e os sindicatos na Itália (35) & I. Séminatore \\
\hline A consciência de classe: do terceiro estado à revolução (281) & M. Joubert \\
\hline Movimento operário e movimento socialista na França (50) & $\begin{array}{l}\text { B. Conein, } \\
\text { M.-N. Thibault, } \\
\text { Fr. Duroux }\end{array}$ \\
\hline \multicolumn{2}{|l|}{ 2. IMPERIALISMO E SUBDESENVOLVIMENTO } \\
\hline Estrutura de classes nas formações dominadas da América Latina (44) & Y. Duroux \\
\hline Estrutura de classes nas formações dominadas da África negra (118) & P.-P. Rey \\
\hline \multicolumn{2}{|l|}{$\begin{array}{l}\text { Estrutura de classes nas formações dominadas do Oriente Médio, } \\
\text { Magrebe e países mediterrâneos }\end{array}$} \\
\hline Algéria, agricultores e imigração (129) & J.-P. Briand \\
\hline Egito (22) & M. Benzine \\
\hline Grécia (55) & C. Tsoucalas \\
\hline $\begin{array}{l}\text { Estrutura de classes nas formações dominadas do Sudeste Asiático } \\
(47)\end{array}$ & $\begin{array}{l}\text { Y. Duroux, } \\
\text { S. Lazarus, } \\
\text { G.Althabe, } \\
\text { C. Mallet, } \\
\text { Ravoajanahary }\end{array}$ \\
\hline \multicolumn{2}{|l|}{$\begin{array}{l}\text { Tipos de intervenção imperialista (países capitalistas e países } \\
\text { socialistas) - Cooperação cultural, presença diplomática, intervenção } \\
\text { militar, investimentos }\end{array}$} \\
\hline Papel das forças armadas na luta de classes (84) & $\begin{array}{l}\text { S. Lazarus, } \\
\text { J.-M. Faure }\end{array}$ \\
\hline
\end{tabular}




\begin{tabular}{|c|c|}
\hline Formas de Estado nos países dominados pelo imperialismo & M. Benzine \\
\hline Sociedades agrárias e subdesenvolvidas (58) & G. Leclerc \\
\hline \multicolumn{2}{|l|}{ 3. PROBLEMAS DO SOCIALISMO } \\
\hline As transformações da agricultura chinesa (95) & J.-M. Faure \\
\hline As relações cidades-interiores (1928-1934) na URSS & J.-M. Faure \\
\hline O debate organizacional $(70)$ & M. Grumbach \\
\hline As relações de trabalho e os sindicatos soviéticos (39) & M. Grumbach \\
\hline O socialismo e a questão das mulheres & C. Dufrancatel \\
\hline $\begin{array}{l}\text { Análise comparativa da formação do Estado soviético e do Estado } \\
\text { chinês (115) }\end{array}$ & S. Lazarus \\
\hline A política externa da República popular da China (120) & C. Mallet \\
\hline O Estado socialista e a guerra (81) & S. Lazarus \\
\hline A gestão das empresas na URSS (18) & A. Bory \\
\hline \multicolumn{2}{|l|}{ 4. PROBLEMAS ATUAIS DO ESTADO } \\
\hline Hegemonia e luta de classes (53) & $\begin{array}{l}\text { B. Conein, } \\
\text { Y. Duroux }\end{array}$ \\
\hline $\begin{array}{l}\text { Classes sociais e partidos políticos (problemas de representação e de } \\
\text { organização) (81) }\end{array}$ & $\begin{array}{l}\text { M. Loewi, } \\
\text { N. Poulantzas }\end{array}$ \\
\hline O Estado socialista e a guerra (cf. grupo problemas do socialismo) & S. Lazarus \\
\hline Formas atuais do Estado nos USA (52) & C.Tsoucalas \\
\hline Os partidos e os sindicatos na Itália (cf. grupo operário) & I. Seminatore \\
\hline $\begin{array}{l}\text { Ditadura cultural e mecanismo da ideologia nos países imperialistas } \\
(69)\end{array}$ & J.-P. Dollé \\
\hline Problema da integração dos sindicatos (cf. grupo operário) & C. Weckerlé \\
\hline $\begin{array}{l}\text { Formas do Estado nos países dominados pelo imperialismo (cf. grupo } \\
\text { imperialista e subdesenvolvimento) }\end{array}$ & M. Benzine \\
\hline \multicolumn{2}{|l|}{ 5. AGRICULTORES E PEQUENA BURGUESIA } \\
\hline As classes sociais no interior nas grandes metrópoles imperialistas (15) & J.-P. Grossein \\
\hline O problema das alianças: agricultores e classes (cf. A classe operária) & C. Weckerlé \\
\hline A burguesia do século XIII ao século XX & $\begin{array}{l}\text { M. Meyer, } \\
\text { P. Sorlin }\end{array}$ \\
\hline Elites e cultura nas formações dominadas (86) & M. Meyer \\
\hline Tipos de intelectuais 1. A imprensa e os jornalistas (65) & $\begin{array}{l}\text { J.-C. Passeron, } \\
\text { H. Peretz, } \\
\text { A. Gras }\end{array}$ \\
\hline \multicolumn{2}{|l|}{ 6. APARELHOS E CONTROLES } \\
\hline \multicolumn{2}{|l|}{ A escola } \\
\hline As ideologias pedagógicas (142) & $\begin{array}{l}\text { B. Conein, } \\
\text { P. de Gaudemar }\end{array}$ \\
\hline Escolarização e sociedade de classe (120) & $\begin{array}{l}\text { J.-M. Chapoulie, } \\
\text { P. de Gaudemar }\end{array}$ \\
\hline Escola e política (48) & J.-M. Chapoulie \\
\hline Escola e mercado de trabalho ( $2^{\circ}$ semestre) & J.-M. Chapoulie \\
\hline Pedagogia, meios de expressão e política (249) & M. Joubert \\
\hline A opinião política - crítica da política das enquetes de sondagens (26) & $\begin{array}{l}\text { C. Dufrancatel, } \\
\text { Darbre }\end{array}$ \\
\hline \multicolumn{2}{|l|}{ Instituições penitenciárias, psiquiatria e para-psiquiatras } \\
\hline Ciclos penitenciários e ciclos psiquiátricos (41) & $\begin{array}{l}\text { R. Castel, } \\
\text { J. Donzelot }\end{array}$ \\
\hline Funcionamento da prática psiquiátrica (21) & E. Wulff \\
\hline Observação etnometodológica do processo (66) & N. Herpin \\
\hline Observação etnometodológica do processo (22) & M. Naffrechoux \\
\hline Policia, justiça, prisão (137) & D. Defert \\
\hline
\end{tabular}




\begin{tabular}{|c|c|}
\hline O dinheiro na prática e na teoria psicanalítica ( $2^{\circ}$ semestre) & J.-P. Grossein \\
\hline Processo de controle dos fatos psiquiátricos e criminológicos (138) & $\begin{array}{l}\text { N. Herpin, } \\
\text { R. Castel }\end{array}$ \\
\hline A infância inadaptada (20) & C. Wagman \\
\hline A família (100) & $\begin{array}{l}\text { C. Dufrancatel, } \\
\text { F. Duroux }\end{array}$ \\
\hline Observação etnometodológica das práticas familiares ( 2 semestre) & N. Herpin \\
\hline \multicolumn{2}{|l|}{ 7. ARTES E URBANISMO } \\
\hline Objeto de uma sociologia urbana (107) & M. Bénard \\
\hline Êxodo rural e urbanismo (43) & M. Bénard \\
\hline Lazer e urbanismo (6) & $\begin{array}{l}\text { M. Bénard, } \\
\text { J.-P. Martinon }\end{array}$ \\
\hline $\begin{array}{l}\text { Metodologia para enquetes sobre especulações e expulsões ( } 3 \\
\text { grupos) (112) }\end{array}$ & D. Defert \\
\hline Objeto de uma sociologia da arte $(38)$ & $\begin{array}{l}\text { R. Lelièvre, } \\
\text { H. Peretz }\end{array}$ \\
\hline Introdução à sociologia e à economia do cinema (56) & M. Jakubowicz \\
\hline Mito e literatura (64) & J.-P. Martinon \\
\hline Os monopólios da produção das normas estéticas (22) & H. Peretz \\
\hline Práticas religiosas e práticas artísticas (54) & R. Lelièvre \\
\hline Funções do discurso de acompanhamento & J.-P. Martinon \\
\hline \multicolumn{2}{|l|}{ 8. UV INTERDISCIPLINARES } \\
\hline A burguesia do século XIII ao século XX & $\begin{array}{l}\text { M. Meyer, } \\
\text { P. Sorlin }\end{array}$ \\
\hline $\begin{array}{l}\text { Movimento operário e movimento socialista na França (A Comuna e } \\
\text { 36) }\end{array}$ & $\begin{array}{l}\text { B. Conein, } \\
\text { M.-N. Thibault, } \\
\text { Fr. Duroux }\end{array}$ \\
\hline Mito e literatura & J.-P. Martinon \\
\hline O racismo & $\begin{array}{l}\text { C. Dufrancatel, } \\
\text { R. Galissot, } \\
\text { M. Rebérioux }\end{array}$ \\
\hline Nacionalismo e questão nacional & $\begin{array}{l}\text { R. Gallissot, } \\
\text { M. Loewy, } \\
\text { N. Poulantzas }\end{array}$ \\
\hline Semiologia: Introdução (92) & L. Prieto \\
\hline Semiologia: seminário sobre a comunicação e o conhecimento (82) & L. Prieto \\
\hline A imagem da mulher na literatura contemporânea (41) & $\begin{array}{l}\text { C. Dufrancatel, } \\
\text { G. Rosowsky, } \\
\text { J. Stora, } \\
\text { B. Slama }\end{array}$ \\
\hline $\begin{array}{l}\text { Ateliê de tradução (alemão), texto sobre a imagem do dinheiro na } \\
\text { psicanálise, a família }\end{array}$ & J.-P. Grossein \\
\hline
\end{tabular}

Fonte: Um Mythe à détruire? op. cit., p. 338. O número entre parênteses após cada título corresponde ao número de UV (unidade de valor) concedidas no $1^{\circ}$ e $2^{\circ}$ semestres (fora adicionais). Ele dá uma ideia do "sucesso" de cada disciplina junto aos estudantes.

\section{Como explica J.-C. Passeron:}

Então, finalmente, eu tinha, apesar de tudo, posto em prática um departamento. E, evidentemente, não queria ser eleito presidente ou 
chefe, em plena crise maoista... Os chefinhos, não sei... Era um coletivo em que todo mundo votava, no entanto eles admitiam segundo seu interesse, certamente (ter cada vez mais, ser mais ou menos titulado, etc.), portanto era melhor que eu fosse o representante externo do departamento. Mas no interior, normalmente, eu não tinha mais direito que os outros na fabricação dos planos de trabalho... Era um caos de conflitos entre as tendências políticas esquerdistas, compostas geralmente por jovens estudantes que não tinham terminado seus estudos, e que eram admitidos como professores substitutos.

A posição descrita por J.-C. Passeron é mais ou menos partilhada pelo conjunto de professores de Vincennes que, mais velhos e dotados de certo capital e/ou ocupando funções de responsabilidade, servem de garantia (intelectual, política, gerencial) à coletividade de Vincennes, tanto do ponto de vista do exterior do departamento, quanto da universidade em seu conjunto, sobretudo nas suas relações com a imprensa, com o ministério, etc. E esse caos não é muito propício ao desenvolvimento de uma "pedagogia racional" coletivamente combinada, porém almejada pelos autores de Os herdeiros. Assim, Robert Castel faz um balanço modesto da experiência:

Acredito que no início deve ter havido um ingresso em Vincennes de pessoas que eram de meios realmente populares, que acreditaram nessa coisa na qual a gente também acreditava um pouco. [...] Mas muitos compreenderam rapidamente que não era assim, que isso sem dúvida não era possível. [...] O ideal um pouco democrático que estava lá desde o começo, bom, isso não se realizou. Bom, por outro lado, isso serviu a pessoas que já estavam lá, que não eram completamente, digamos, de meios populares, salvo excepcionalmente. Frequentemente eram pessoas que tinham uma trajetória um pouco universitária, mas que tinham fracassado, ou então não tinham continuado. Ao menos isso lhes serviu. $^{22}$

Finalmente, uma das principais inovações pedagógicas de Vincennes resulta na invenção de um tipo de mercado livre acadêmico no qual cada professor era posto em concorrência carismática com todos os outros na captação da clientela estudantil, situação propícia também a todos os excessos demagógicos ou clientelistas. Assim, o questionamento da relação de dominação pedagógica tradicional levara à constituição de

\footnotetext{
${ }^{22}$ Entrevista com R. Castel realizada em 06 de dezembro de 2007.
} 
um mercado livre em que cada estudante deveria saber maximizar seus benefícios, quer no campo intelectual, político, acadêmico ou outro. Resultado no mínimo paradoxal tratando-se de uma instituição tão esquerdista quanto Vincennes e que, de certo modo, explicita muitas ambiguidades, ou ao menos a complexidade da herança política da época, pois em seguida alguns desses esquerdistas fizeram uma bela carreira na imprensa ou se tornaram hábeis homens de negócios.

\section{Classes sociais de origem, trajetórias e orientações pedagógicas}

Sobre a democratização do acesso ao saber, o balanço de Vincennes é de certo modo modesto. E isso em razão sobretudo das suas "escolhas" pedagógicas particularmente "liberais", as quais não facilitaram muito a orientação dos estudantes sem bacharelado, os mais distantes da cultura legítima. Estes, em vários cursos, ficaram de certo modo entregues a si mesmos ante o emaranhado de disciplinas propostas. Escolhas entre aspas, pois resultavam essencialmente das circunstâncias e relações de forças políticas do momento. E é sem dúvida por essa razão que Jean-Claude Passeron afirma que Vincennes era "um universo não pedagógico", fazendo um balanço relativamente crítico dessa experiência:

Enfim, eu queria ver o que poderia restar de pedagógico de uma situação como essa. E então sem que isso fosse um inconveniente, eu apontei com o dedo a impossibilidade de praticar em Vincennes um recomeço pedagógico, ao menos para os estudantes. [...] Uma coisa é certa, a desordem nunca produz o reformismo. Veja, no primeiro ano houve uma boa vontade, inclusive reformista, essa era a língua que se falava, quando a gente se reunia - porque havia comissões em Vincennes. Por exemplo, havia a comissão para as Unidades de Valor - como fazer em relação aos exames? Havia o representante de... Para história era quase sempre Madeleine Rebérioux, que tinha quase a mesma posição que eu: ou seja, retirar alguma coisa dessa atmosfera revolucionária, retirar algo disso. Como eu. E havia representantes de todos os departamentos, e a maioria era reformista. Mas na filosofia, eles não vinham... (Apud SOULIÉ, 2012, p. 223). 
Ao contrário, é evidente que a experiência de Vincennes respondeu a uma grande demanda social, ou para utilizar o vocabulário deleuziano, a um "desejo" particularmente poderoso. Demanda amplamente determinada pela conjuntura social, política e cultural do momento e muito mais pelos efeitos de longo prazo da crise de 68 sobre a sociedade francesa. Demanda sobre a qual também se pode perguntar se não seria apresentada especialmente por algumas classes, ou frações de classes. E aqui, pensamos sobretudo nas análises que em 1979 Pierre Bourdieu desenvolve em A Distinção a propósito dos membros da "nova pequena burguesia" que, como ele escreve na época, estão ligados à "educação permanente", mantêm "uma relação ambivalente com o sistema escolar", o que os leva "a se sentirem cúmplices de toda espécie de contestação simbólica". Eles fazem aliança com a vanguarda acadêmica do momento em luta contra a antiga Sorbonne.

No caso de Vincennes, parece que em torno das questões pedagógicas e sobretudo de formalização dos currículos, do grau de exigência imposto aos estudantes, etc., assistiu-se a uma luta entre grupos sociais antagônicos com interesses mais ou menos divergentes e portanto a uma forma de luta de classes mais ou menos negada. Assim, parece que as opções pedagógicas mais liberais e carismáticas foram preferencialmente realizadas pelos professores e estudantes de origem social mais elevada (ou mais precisamente em fase de desclassificação), enquanto os de origem popular, ou em fase de ascensão social, defenderam opções mais escolares e regradas, claramente em harmonia com os imperativos da acumulação de um capital escolar necessário ao seu projeto de ascensão social ${ }^{23}$. Essa oposição confirma também certas oposições políticas mais ou menos gerais (entre "antiparticipação" e "participantes", "revolucionários" e "reformistas"). Isso coloca a questão da definição prática da “pedagogia racional” desejada por Bourdieu e Passeron, assim como por forças sociais e políticas suscetíveis de levar adiante tal projeto pedagógico.

\footnotetext{
23 "Vale lembrar que, na história das utopias pedagógicas, o ideal de um ensino sem instituição nem sanção, liberado das rotinas e dos controles plebeus dos 'homens de métier' e visando a despertar no aluno dons ou verdades que ele já possui, quase sempre coincidiram com uma representação aristocrática das disciplinas dignas de satisfazê-lo?” (GÉRALD e PASSERON, 1966, p. 214).
} 


\section{Referências}

BOURDIEU, Pierre e DARBEL, Alain. L'Amour de l'art. Paris: Éditions de Minuit, 1966.

BOURDIEU, Pierre. Homo academicus. Paris: Éditions de Minuit, 1984.

BOURDIEU, Pierre; PASSERON, Jean-Claude. La reproduction, éléments pour une théorie du système d'enseignement. Paris: Éditions de Minuit, 1970.

BOURDIEU, Pierre; PASSERON, Jean-Claude. Les héritiers: Les étudiants et la culture. Paris: Éditions de Minuit, 1964.

BRUNET, Jacqueline et al. Vincennes ou le désir d'apprendre. Paris: Éditions Alain Moreau, 1979.

BUÉ, Alain. Josué de Castro, un visionnaire brésilien à Vincennes: Mário Soares, "Exilé en cravate". In DJIAN, Jean-Michel. Vincennes, une aventure de la pensée critique. Paris: Flammarion, 2009, p. 126-129.

CASTEL, Robert. e PASSERON, J.-C. Éducation, développement et démocratie. Paris-La Haye: Mouton, 1967.

CHARBONNIER, Sébastien. Deleuze pédagogue, la fonction transcendantale de l'apprentissage et du problème. Paris: L'Harmattan, 2009.

CHÂTELET, François. Disparité et non hiérarchie". BRUNET, Jacqueline et al. Vincennes ou le désir d'apprendre. Paris: Éditions Alain Moreau, 1979, p. 126 e seguintes.

DELEUZE, Gilles e GUATARRI, Félix. L'Anti-CEdipe. Capitalisme et schizophrénie. Paris: Éditions de Minuit, 1972.

DELEUZE, Gilles. L'Abécédaire de Gilles Deleuze. In BOUTANG, Pierre-André (Dir.). Paris: Éditions du Montparnasse, 2004 (filme).

FAURE, Edgar. Philosophie d'une réforme. Paris: Plon, 1969.

FOSSE-POLLIAK, Claude. L'accès dérogatoire à l'enseignement supérieur, les autodidactes de Saint-Denis. Revue française de sociologie, XXXII, 1991.

FOUCAULT, Michel. Dits et écrit 1954-1988, II, 1970-1975. Paris: Gallimard, 1994, p. 190-191.

GÉRALD, Antoine e PASSERON, Jean-Claude. La Réforme de l'université. Paris: CalmannLévy, 1966.

LE GALL, Brice e SOULIÉ, Charles. Voyage en terre d'asile académique: éléments pour une histoire sociale des étudiants étrangers de Paris VIII et d'ailleurs. In SOULIÉ, Charles (Dir.). Un mythe à détruire? Origenes et destin du Centre universitaire expérimental de Vincennes. Saint-Denis: Presses Universitaire de Vincennes, 2012, p. 393-422.

LEGOIS, Jean-Philippe. Jeux d'échelle entre les premiers pouvoirs universitaires vincennois, 1968-1971. In SOULIÉ, Charles (Dir.). Un mythe à détruire? Origenes et destin 
du Centre universitaire expérimental de Vincennes. Saint-Denis: Presses Universitaire de Vincennes, 2012, p. 259-277.

PAROT, Françoise e RICHELLE, Marc Autobiographie de Jean-François Le Ny. In PAROT, Françoise e RICHELLE, Marc. (Dir.). Psychologues de langue française, autobiographies, Paris: Presses Universitaire de France, 1992, p. 277-278.

PASSERON, Jean-Claude. 1950-1980: I'université mise à la question: changement de décor ou changement de cap? In VERGER, Jacques (dir.). Histoire des universités en France.

Toulouse: Privat, 1986.

POULY, Marie-Pierre. L'anglais de la Sorbonne à Vincennes. In SOULIÉ, Charles (Dir.). Un mythe à détruire? Origenes et destin du Centre universitaire expérimental de Vincennes. Saint-Denis: Presses Universitaire de Vincennes, 2012, p. 282-313.

PROST, Antoine. Histoire générale de l'éducation. Paris: Perrin, vol. IV, 2004.

SOULIÉ, Charles. Le destin d'une institution d'avant-garde: histoire du département de philosophie de Paris VIII. Histoire de l'éducation, $n^{\circ} 77,1998$, p. 62, disponível: http://www.ipt.univ-paris8.fr/hist/HistoireduDptdephilodeParis8a.htm.

SOULIÉ, Charles. Un mythe à détruire? Origenes et destin du Centre universitaire expérimental de Vincennes (Dir.). Saint-Denis: Presses Universitaire de Vincennes, 2012.

Recebido em: 20/08/2013 Aprovado em: 10/02/2014 
Revista Linhas

Volume 15 - Número 29 - Ano 2014 revistalinhas@gmail.com 